\title{
Psychometric properties of the multidimensional assessment of interoceptive awareness (MAIA) in a Chilean population
}

\section{Camila Valenzuela-Moguillansky ${ }^{1}$ and Alejandro Reyes-Reyes ${ }^{2}$}

1 Instituto de Sistemas Complejos de Valparaíso, Valparaíso, Chile

${ }^{2}$ Escuela de Psicología, Universidad Santo Tomás, Concepción, Chile

\section{Edited by:}

Norman Farb, Baycrest, Canada

Reviewed by:

Ruth Baer, University of Kentucky, USA

Michael Acree, University of California, USA

\section{${ }^{*}$ Correspondence:}

Camila Valenzuela-Moguillansky, Instituto de Sistemas Complejos de Valparaíso, Subida Artillería 470, Valparaíso 2360448, Chile e-mail: camilavalenzuelamogui@ gmail.com
The multidimensional assessment of interoceptive awareness (MAIA) is an instrument designed to assess interoceptive awareness. The aim of this study was to adapt the original MAIA scale to Spanish and to analyze its psychometric properties in a Chilean population. The MAIA was administered to 470 adults, aged $18-70$ years, $76.6 \%$ women and $23.4 \%$ men, residents of the provinces of Valparaíso and Concepción, Chile. Exploratory factor analysis reduced the scale from 32 to 30 items. Confirmatory factor analysis supports a structure of eight interrelated factors (Noticing, Not-Distracting, Not-Worrying, Attention Regulation, Emotional Awareness, Self- Regulation, Body Listening, and Trusting), similar to the original scale $\left(\chi^{2}{ }_{(371)}=659.78, p=0.0001 ; C F I=0.92, T L I=0.91, \operatorname{RMSEA}=0.056\right.$ and SRMR $=0.059$ ). The Spanish version showed appropriate indicators of construct validity and reliability, with a Cronbach's $\alpha$ of 0.90 for the total scale, and values between 0.40 and 0.86 for the different subscales. Similar to previous studies, low reliability was observed in two of the eight scales (Not-Distracting and Not-Worrying), thus further revision of these subscales is suggested. The Spanish version of MAIA proved to be a valid and reliable tool to investigate interoceptive awareness in the Chilean population.

Keywords: interoceptive awareness, body awareness, multidimensional assessment of interoceptive awareness, psychometrics properties, mind-body

\section{INTRODUCTION}

This article presents the adaptation into the Spanish language of the multidimensional assessment of interoceptive awareness (MAIA) self-report instrument developed by Mehling et al. (2012), and the evaluation of its psychometric properties in the Chilean population.

Interoceptive awareness relates to the conscious perception of our internal state. Originally introduced by Sherrington (1906), the term interoception has been linked to visceral sensitivity, meaning the ability to detect the signals coming from our "internal milieu." Recently, this term has been redefined as the sense of the physiological condition of the body and not only the viscera (Craig, 2002). This redefinition expands the notion of interoception, placing it as the afferent pathway of the autonomic nervous system. Under this view, afferent signals from the various tissues of the body, which contribute to the regulation of physiological parameters, constitute "a basis for the subjective evaluation of one's condition," in other words, the basis for interoceptive awareness. The link between interoception and interoceptive awareness opens the door to the potential mechanisms underlying the relationship between organic function of our body and our mental and emotional experience.

The meaning of "interoceptive awareness," however, varies depending on the discipline and on the method used to evaluate it. For example, a method widely used to assess interoceptive awareness is cardiac monitoring. This method measures the person's ability to detect his or her own heartbeat. In such a case, the internal state refers to the heartbeat signal, and interoceptive awareness is defined as the ability to count one's own heartbeats. However, if we evaluate interoceptive awareness using the method of stimulation of the gastrointestinal tract, the internal state refers to the induced stimulation on the gastrointestinal tract and interoceptive awareness is defined as the ability to detect gastrointestinal signals. Typically, high interoceptive awareness assessed using such methods is related to maladaptive personality traits associated with states of anxiety and emotional liability (Schandry, 1981; Ehlers and Breuer, 1992). It is not clear whether such methods assess what Craig (2002) refers to with "subjective evaluation of one's condition, that is, how you feel." This description seems closer to a more global awareness of our internal state, such as being able to identify whether we feel at ease, or distressed. This kind of interoceptive awareness is heightened through practices, such as Yoga and Mindfulness Meditation, which develop a particular kind of attention toward the body and toward the person's internal state, characterized by a receptive attitude (i.e., Ditto et al., 2006; Kabat-Zinn, 2008). While interoceptive awareness assessed by the methods measuring cardiac or gastrointestinal awareness focuses on perturbed physical states, awareness developed through these practices has a beneficial impact in a person's physical and mental health (i.e., Chow and Tsang, 2007; Davis et al., 2007; Rosenzweig et al., 2007; Morone et al., 2008). These differences highlight that different ways of attending to the body, some adaptive while others not, might be grouped under the same concept. 
The scale adapted in the present study aims to contribute in distinguishing these different modes of interoceptive awareness to serve as a tool for experimental interoception research, and for assessment of mind-body therapies.

Multidimensional assessment of interoceptive awareness was developed through a systematic mixed-methods process involving reviewing the current literature, specifying a multidimensional conceptual framework, evaluating prior instruments, developing items, and analyzing focus group responses to scale items by instructors and patients of body awareness-enhancing therapies (Mehling et al., 2012). It was refined by cognitive interviews, and items were field-tested in students and instructors of mindbody approaches. Field test data were submitted to an iterative process using multiple validation methods, including exploratory cluster and confirmatory factor analyses, comparison between known groups, and correlations with established measures of related constructs (Mehling et al., 2012). The resulting 32-item multidimensional instrument is composed of eight subscales: (1) Noticing: the awareness of uncomfortable, comfortable, and neutral body sensations; (2) Not-Distracting: the tendency to ignore or distract oneself from sensations of pain or discomfort; (3) Not-Worrying: emotional distress or worry with sensations of pain or discomfort; (4) Attention Regulation: the ability to sustain and control attention to body sensation; (5) Emotional Awareness: the awareness of the connection between body sensations and emotional states; (6) Self-Regulation: the ability to regulate psychological distress by attention to body sensations; (7) Body Listening: actively listening to the body for insight and (8) Trusting: experiencing one's body as safe and trustworthy.

Multidimensional assessment of interoceptive awareness's convergent and divergent validity was tested using different published measures of constructs related to body awareness. Aspects of mindful attention and body awareness were assessed with the Five Factor Mindfulness Questionnaire (FFMQ), the Private Body Consciousness Subscale (PBCS) of the Body Consciousness Questionnaire and the Body Responsiveness Questionnaire (BRQ). Aspects of anxiety as a state or trait, or as distress in response to bodily symptoms or pain, were assessed with the physical concern subscale (ASI-PC) of the Anxiety Sensitivity Index (ASI), the Pain Catastrophizing Scale (PCS) and the State-Trait Anxiety Inventory (STAI), which assessed convergent validity of the MAIA Not-Worrying subscale.

Multidimensional assessment of interoceptive awareness has been translated into nine languages. To our knowledge, the only adaptation to date that has published the assessment of its psychometric properties is the German version. Bornemann et al. (2014) analyzed whether the factor structure of the English MAIA would replicate in the German version. The exploratory factor analysis (EFA) showed that the German version has eight factors that group items in the same manner as the English version, with the exception of item 19 that loaded Emotional Awareness and Body Listening equally.

This article presents the translation and adaptation procedure of the MAIA tool to a Spanish version, and the evaluation of its psychometric properties applied to a Chilean population.

\section{METHODS}

\section{PARTICIPANTS}

The sample consisted of 470 participants, aged between 18 and 70 years $(M=30.52, S D=10.60)$, from the provinces of Valparaíso and Concepción, Chile. $76.6 \%$ were female and $23.4 \%$ male with no statistically significant differences in age $\left(t_{(207.479)}=0.567, p=0.572\right)$. The sample included undergraduate students $(n=205 ; 43.6 \%)$, graduate students $(n=98 ; 20.9 \%)$, university professionals from different areas $(n=142 ; 30.2 \%)$ and people with secondary or lower level of education $(n=25 ; 5.3 \%)$.

\section{INSTRUMENT}

The MAIA is a self-administered instrument developed by Mehling et al. (2012) to measure eight dimensions of interoceptive body awareness. It has a total of 32 items tested on a Likert scale, with six levels of ordinal response coded from 0 (never) to 5 (always), generating a total direct score on a scale that ranges from 0 to 160 points. The number of items and reliability established by Cronbach's alpha $(\alpha)$, vary among the subscales: noticing (four items, $\alpha=0.69$ ), Not-Distracting (three items, $\alpha=0.66$ ), NotWorrying (three items, $\alpha=0.67$ ), Attention Regulation (seven items, $\alpha=0.87$ ), Emotional Awareness (five items, $\alpha=0.82$ ), SelfRegulation (four items, $\alpha=0.83$ ), Body Listening (three items, $\alpha=0.82$ ) and Trusting (three items, $\alpha=0.79$ ). The Spanish version of the scale preserved the extension, format and dimensional structure of the original version.

\section{PROCEDURE}

The Institutional Bioethics Committee of the University of Valparaíso (Chile) approved the study. Three stages were conducted for the translation and adaptation of the questionnaire: translation, cognitive interviews and survey.

\section{Spanish translation}

The translation was based on the original English version of MAIA. Before carrying out the translation, agreement was obtained from the first author of the scale [Wolf Mehling (W.M.)]. A forwardbackward translation was performed comprising the following steps:

- Three independent forward translations were made: two by bilingual Spanish native translators who didn't know the construct and one by a bilingual Spanish native person who was familiar with the construct.

- The three versions were compared and, after consensus between the two translators and the project manager, a single document was drafted.

- An English native bilingual translator, who was not familiar with the construct, performed the back-translation into English.

- Divergences between the back-translation and the original English version were identified and discussed with the first author of the original scale. For the items where cross-language agreement could not be reached, Spanish sentences were reworded.

\section{Cognitive interviews}

The cognitive interviews sample included thirteen people aged 21 to $72(M=42.8 ; S D=15.6)$, with education level 
from high school to graduate school. Five persons were "body awareness-experienced." Two persons had chronic pain. The sample was primarily female $(n=10)$.

Interviewees were asked to complete the MAIA and note next to each item whether they had any doubts or comments. On completing the survey, they filled a Participants Information Form and a cognitive interview was conducted. One half of participants were asked in-depth questions for all items while the other half were asked in-depth questions where they had noted concerns, or that had been identified as potentially conflicting by our research team. Interviews began with "Did this item make sense to you?" followed by "can you elaborate?" For the items identified as potentially conflicting, specific questions were elaborated. Results from the cognitive interviews were discussed with the first author of the scale, and changes were made when considered appropriate.

\section{Survey}

The scale was self-administered using a web platform with the exception of 90 undergraduate students who completed a paper survey. In both modalities (web-survey and paper), participants were explained the purpose of the study, were informed that they would not be compensated for their participation, that they were free to respond and that by agreeing to answer the scale they were giving their informed consent to participate in the study. In the web version this information was presented before the scale. In addition, it was explained that the research manager could be reached by email to respond to any questions concerning the study.

A participants information form was used to collect the demographic characteristics of participants (age, gender, educational level, presence of chronic pain, treatment, medication, and level of practice in five different body-mind techniques). This was followed by the Spanish version of the MAIA, after which there were two additional questions assessing whether participants had any problems with any of the scale items.

A pre-test with 12 subjects was conducted for the web-survey to verify comprehensiveness, ease of use of the web interface, and that data were correctly recorded, stored, and able to be exported. The mean duration of the survey was about $9 \mathrm{~min}$, which was judged acceptable. The web platform used was Surveygizmo.

\section{DATA ANALYSIS}

Missing values were imputed using the Markov Chain Monte Carlo (MCMC) method. From the total of 470 responses per item, there were 1-7 missing values in 28 items.

To evaluate the factorial structure of the scale, a cross-validation procedure was implemented where the total sample $(n=470)$ was randomly divided in two subsamples: a training sample $(n=220$, $46.8 \%)$ and a validation sample $(n=250,53.2 \%)$. The training sample was used to carry out an EFA to identify the factor structure of the MAIA. Estimation of the factors was performed by factoring the Pearson correlation matrix by the maximum likelihood (ML) method with an oblique Promax rotation. Parallel analysis (PA), the goodness of fit index (GFI) and the root mean square error of approximation (RMSEA) were used to select the factors. The validation sample was used to perform confirmatory factor analysis (CFA), testing the factorial structure obtained with the EFA.

Factor loadings with a minimum value in the range of \pm 0.30 were considered as building criteria for the EFA model (Hair et al., 2010). In the CFA, a good fit for a model was considered when the chi-square statistic $\left(\chi^{2}\right)$ was not significant, the root mean square error of approximation (RMSEA) $<0.08$ and comparative fit index (CFI), GFI index and non-normed fit index (NNFI or TLI) > 0.95 (Hu and Bentler, 1999; Kline, 2011; West et al., 2012).

Cronbach's alpha coefficient was used to establish the reliability of the scale and subscales. To examine associations between items and relationship between subscales, the Pearson correlation matrix was used.

Statistical analyses were performed using IBM SPSS Statistics 20 (IBM Corp.), IBM SPSS AMOS 18 (IBM Corp.) and FACTOR 9.30 (Lorenzo-Seva and Ferrando, 2006) programs.

\section{RESULTS}

\section{TRANSLATION AND COGNITIVE INTERVIEWS}

From the cognitive debriefing interviews we identified four main conflicting issues. These were discussed with the first author of the original scale (W.M.)

- Twelve out of thirty two items are formulated using "Puedo..." (I can...). This formulation appeared ambiguous to several interviewees since they didn't know whether they should respond what they potentially could do, or what they actually do. This remark, more than a translation issue, was intentional in the design of the original scale. After discussion with W.M., we decided to leave the original formulation.

- The reverse item 5 was formulated using negation, which confused several interviewees. Mehling et al. (2013) also reported problems with item 5 and suggested: “. . .this item may have to be dropped or reworded in any future studies." Consulting with W.M., we reformulated item 5, removing the negation: instead of "I do not notice (I ignore) physical tension or discomfort until they become more severe," the Spanish version was "Noto la tensión física o el malestar solamente cuando se vuelve muy severo" [ I notice physical tension or discomfort only when they become very severe].

- The reverse item 6 in the original English version (I distract myself from sensations of discomfort) was formulated using an affirmation. However, in Spanish, the formulation "me distraigo" was considered an active voluntary attitude that differed from the connotation in English. We translated this item using a negation: "No me doy cuenta de las sensaciones de malestar" [I don't notice sensations of discomfort]. Some interviewees expressed confusion regarding this formulation. However, the negation was maintained following discussion with W.M.

- Some participants described certain items as lacking in context to situate an affirmation. For instance, some interviewees didn't understand item 15 (I can refocus my attention from thinking to sensing my body), or found it awkward, arguing that it depends on the context whether they would do that. Following review with W.M, we considered that this was a general issue of the MAIA depending on the participant's familiarity with mindbody practices. Thus, we decided not to change the item. 
- Although generally participants did not have problems with item 7 (When I feel pain or discomfort, I try to power through it), through the interviews we realized that the term "sobrepasar" used to translate "to power through it" was ambiguous. When asked what do they do to "sobrepasar" there was a variety of responses, and each participant attributed a different meaning to the word. After discussing with the first author of the original scale, we changed this item to: "Cuando siento dolor o malestar intento ignorarlo y continuar con lo que estaba haciendo" [When I feel pain or discomfort, I try to ignore it and to carry on with what I was doing].

\section{SURVEY}

The assessment of assumptions necessary for the use of factor analysis showed a Kaiser-Meyer-Olkin (KMO) sampling adequacy of 0.884 , and a significant Bartlett test of sphericity $\left(\chi^{2}=3416.8\right.$; $p<0.001)$. This supports factor analysis as an appropriate model for analyzing the data. Since the items of the scale had an ordinal polyatomic response, assumption of a multivariate normal distribution is not met. Assessment of skewness and kurtosis showed that most values were in the range -1 and 1 (see Table 1). There were seven items that exceeded this criterion, but remained in the range $-1.5-1.5$ : only Item 2 was outside this range. This allows inferring an approximation of each item to a Normal distribution (Lloret-Segura et al., 2014). Such statistics, coupled with the property that each item has six response levels, enables the use of the ML method to estimate the model parameters. This method has demonstrated robustness when the assumption of multivariate normality fails, and when there is an approximately normal univariate distribution (Forero et al., 2009).

Using the training sample $(n=220)$ successive factorial solutions were obtained using ordinary least squares (OLS) and ML method combined with the oblique rotations Direct Oblimin, Promin, and Promax. Factor solutions with six, seven, and eight factors were analyzed.

Results of the six-factor solutions generate a single factor for items $5,6,7,8$, and 9 , but showed several factor loadings lower than 0.30. Items from 19 to 28 formed a single factor with factor loadings higher than 0.60 . Solutions based on seven factors tended to differentiate two factors amongst items $5,6,7,8$, and 9. Items from 19 to 28 remained as a single factor, with factor loadings higher than 0.60 Among solutions based on eight factors, a model was found with loadings greater than or equal to 0.30 , where seven of the eight factors comprised three or more items. The eight factors model achieved the greatest quality and was used to perform the CFA. As an analytic strategy, we used the ML method with normalized Promax rotation calculated with FACTOR 9.30. The factor structure matrix is shown in Table 2.

The commonalities reproduced by the rotated factor solution ranged between. 36 and.93, where the eight extracted factors explained $67.2 \%$ of the total variance. The factorial structure had low factor loading in items $8(0.29)$ and $9(0.27)$, which does not allow specifying the Not-Worrying subscale. The remaining factor loadings were above.40, considered significant for a sample size of 200 (Hair et al., 2010).
Table 1 | Univariate descriptives statistics for the items $(n=220)$.

\begin{tabular}{|c|c|c|c|c|c|c|}
\hline \multirow{2}{*}{$\begin{array}{l}\text { Item } \\
\text { Item } 1\end{array}$} & \multirow{2}{*}{\begin{tabular}{|l} 
Mean \\
3.841
\end{tabular}} & \multicolumn{2}{|c|}{$\begin{array}{c}\text { Confidence } \\
\text { interval }(95 \%)\end{array}$} & \multirow{2}{*}{$\begin{array}{l}\text { Variance } \\
1.652\end{array}$} & \multirow{2}{*}{$\begin{array}{l}\text { Skewness } \\
-1.146\end{array}$} & \multirow{2}{*}{$\begin{array}{c}\text { Kurtosis } \\
0.853\end{array}$} \\
\hline & & 3.62 & 4.06 & & & \\
\hline Item 2 & 4.182 & 3.99 & 4.38 & 1.267 & -1.669 & 2.762 \\
\hline Item 3 & 3.336 & 3.09 & 3.58 & 2.032 & -0.674 & -0.310 \\
\hline Item 4 & 3.782 & 3.54 & 4.02 & 1.971 & -1.112 & 0.381 \\
\hline Item 5 & 2.400 & 2.15 & 2.65 & 2.104 & 0.061 & -0.925 \\
\hline Item 6 & 3.277 & 2.96 & 3.59 & 3.282 & -0.658 & -1.022 \\
\hline Item 7 & 2.205 & 1.94 & 2.47 & 2.399 & 0.400 & -0.806 \\
\hline Item 8 & 2.809 & 2.54 & 3.08 & 2.445 & -0.318 & -0.913 \\
\hline Item 9 & 2.136 & 1.87 & 2.40 & 2.336 & 0.252 & -0.927 \\
\hline Item 10 & 2.045 & 1.78 & 2.31 & 2.352 & 0.257 & -1.024 \\
\hline Item 11 & 2.850 & 2.59 & 3.11 & 2.328 & -0.239 & -0.936 \\
\hline Item 12 & 3.232 & 2.98 & 3.48 & 2.105 & -0.544 & -0.624 \\
\hline Item 13 & 3.077 & 2.81 & 3.35 & 2.444 & -0.552 & -0.760 \\
\hline Item 14 & 3.245 & 3.00 & 3.49 & 2.076 & -0.628 & -0.483 \\
\hline Item 15 & 3.345 & 3.12 & 3.57 & 1.653 & -0.498 & -0.269 \\
\hline Item 16 & 2.777 & 2.54 & 3.01 & 1.855 & -0.068 & -0.676 \\
\hline Item 17 & 3.127 & 2.89 & 3.36 & 1.820 & -0.512 & -0.336 \\
\hline Item 18 & 3.627 & 3.39 & 3.87 & 1.907 & -0.974 & 0.199 \\
\hline Item 19 & 3.827 & 3.60 & 4.05 & 1.716 & -1.238 & 0.970 \\
\hline Item 20 & 4.027 & 3.82 & 4.23 & 1.399 & -1.294 & 1.053 \\
\hline Item 21 & 3.991 & 3.77 & 4.22 & 1.682 & -1.390 & 1.278 \\
\hline Item 22 & 4.086 & 3.89 & 4.28 & 1.306 & -1.308 & 1.218 \\
\hline Item 23 & 2.764 & 2.51 & 3.02 & 2.153 & -0.305 & -0.689 \\
\hline Item 24 & 2.655 & 2.41 & 2.90 & 2.008 & -0.172 & -0.730 \\
\hline Item 25 & 3.323 & 3.07 & 3.58 & 2.164 & -0.690 & -0.375 \\
\hline Item 26 & 2.841 & 2.58 & 3.10 & 2.252 & -0.310 & -0.912 \\
\hline Item 27 & 2.886 & 2.62 & 3.15 & 2.319 & -0.304 & -0.854 \\
\hline Item 28 & 2.355 & 2.09 & 2.62 & 2.392 & 0.074 & -0.993 \\
\hline Item 29 & 2.400 & 2.14 & 2.66 & 2.240 & -0.076 & -0.942 \\
\hline Item 30 & 3.150 & 2.89 & 3.41 & 2.300 & -0.405 & -0.811 \\
\hline Item 31 & 3.200 & 2.94 & 3.46 & 2.269 & -0.496 & -0.701 \\
\hline Item 32 & 3.645 & 3.42 & 3.88 & 1.774 & -0.987 & 0.318 \\
\hline
\end{tabular}

Considering the results of the EFA, items 4 and 8 were removed from the analysis since they did not contribute to the factor where they theoretically belong. Thus, the rotated factorial matrix was established for the instrument with 30 items (see Table 3).

Similar to the original scale, a structure of eight factors produced the best fit, however, item 9 achieved a factor loading of 0.23 , considered insignificant for the sample size (Hair et al., 2010). Higher factor loadings for item 9 were achieved when the sample size increased: it was thus maintained to preserve the Not-Worrying subscale. The factor loadings of the other scale 


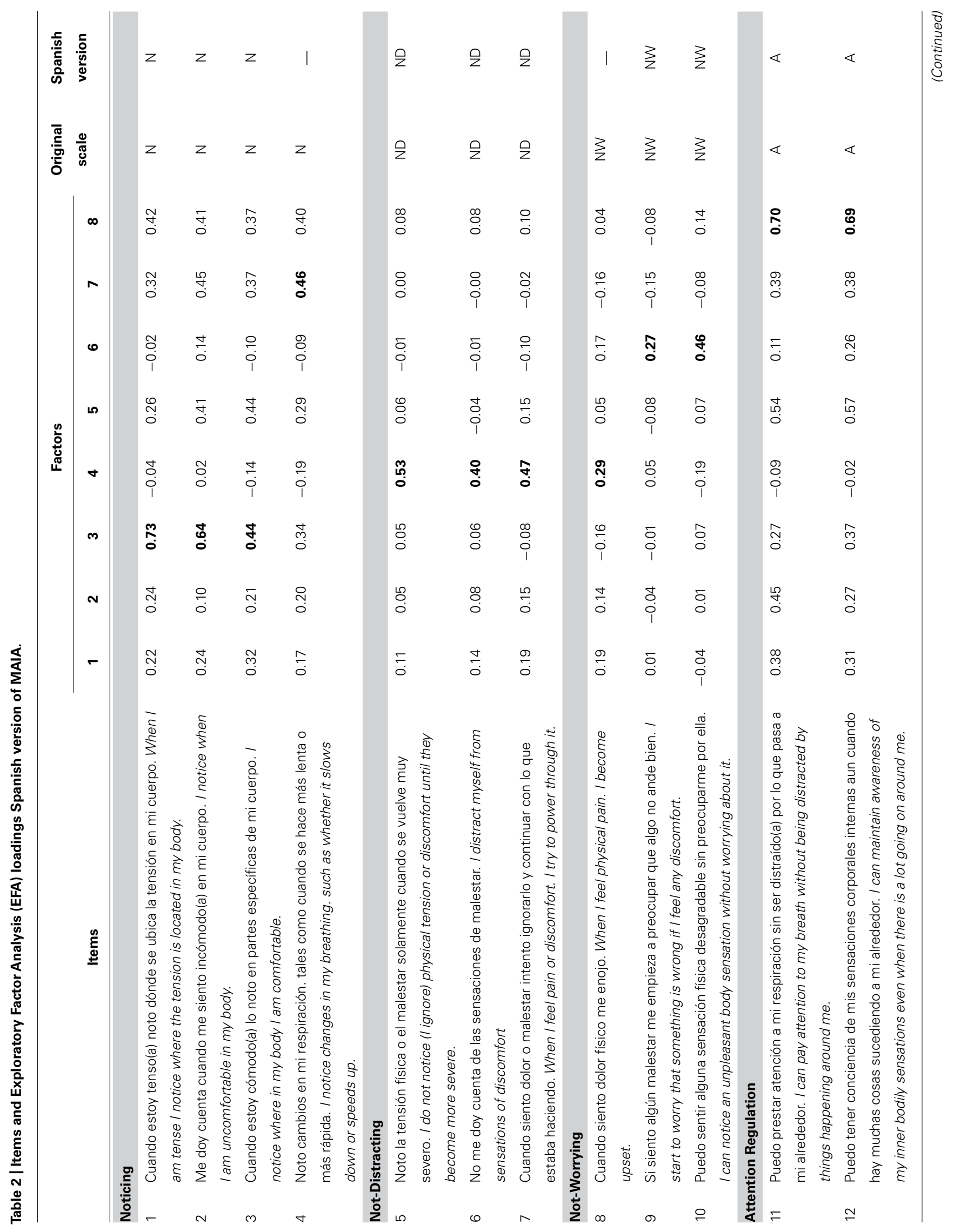




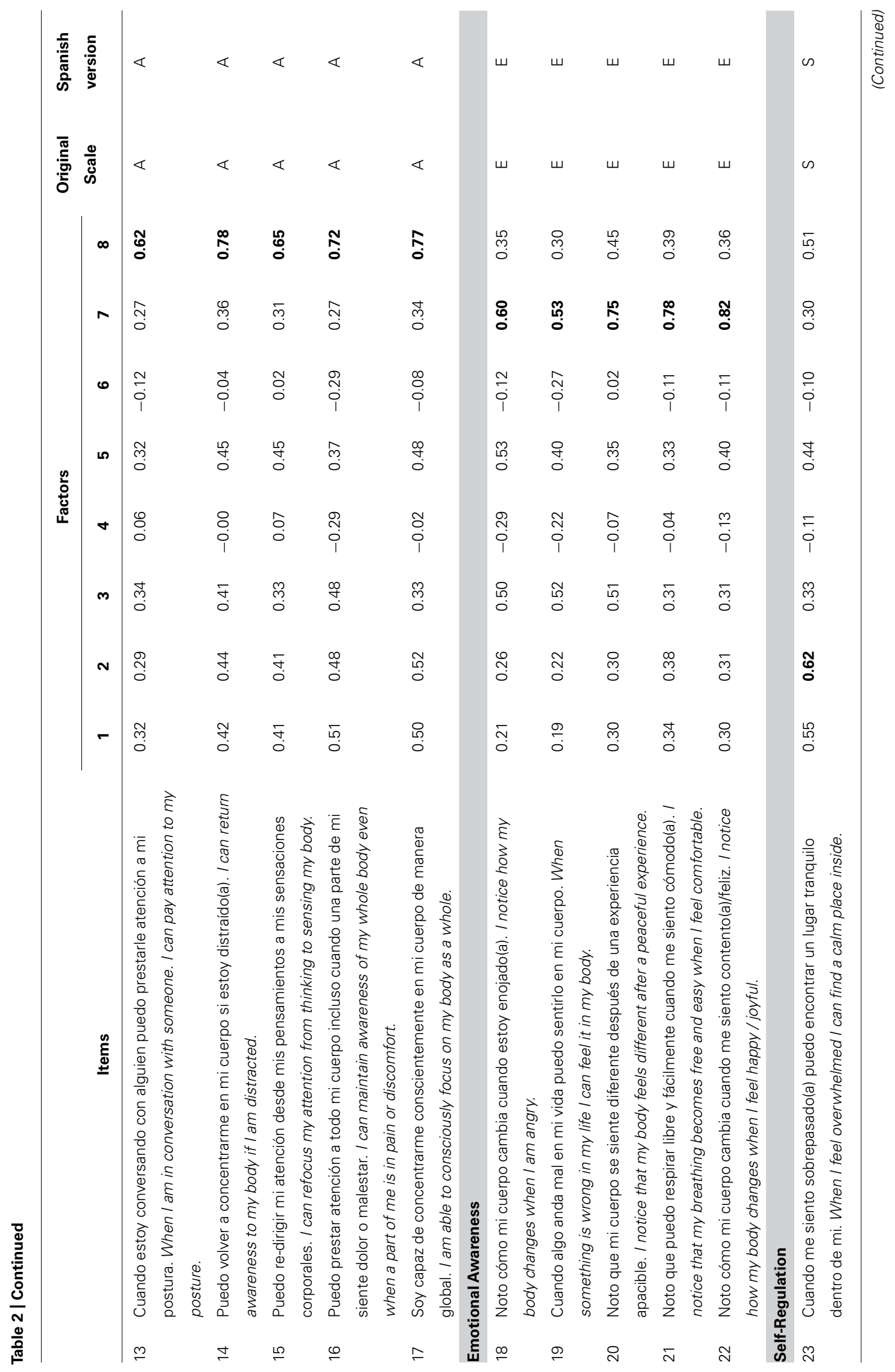




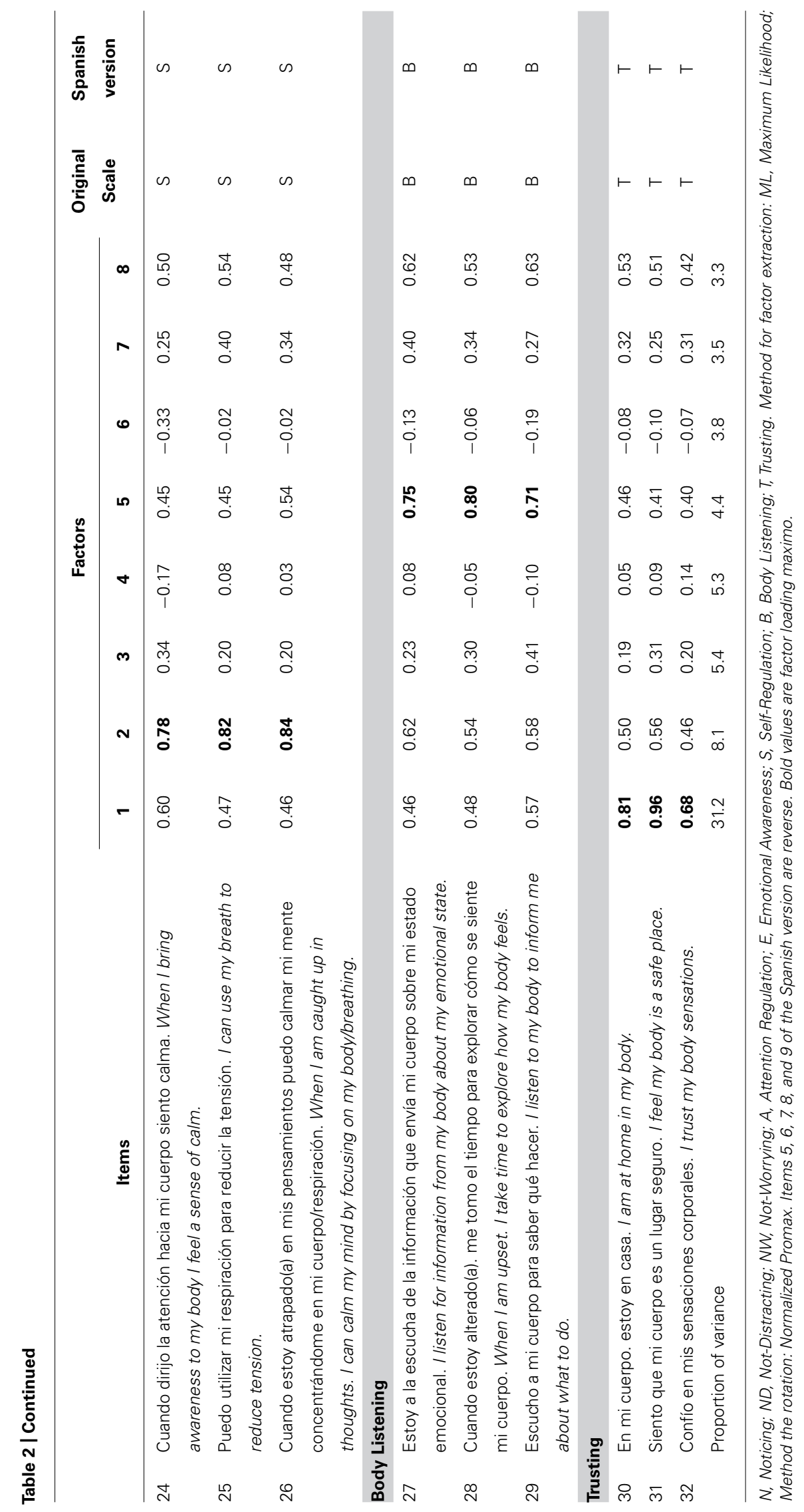


Table 3 | Items, communality and exploratory factor analysis (EFA) loadings Spanish version of MAIA.

\begin{tabular}{llcl}
\hline Noticing & FL & C \\
\hline $1 \quad \begin{array}{l}\text { Cuando estoy tenso(a) noto dónde se ubica la } \\
\text { tensión en mi cuerpo. }\end{array}$ & 0.73 & 0.77 \\
$2 \quad \begin{array}{l}\text { Me doy cuenta cuando me siento incómodo(a) en } \\
\text { mi cuerpo. }\end{array}$ & 0.66 & 0.80 \\
$\begin{array}{l}\text { Cuando estoy cómodo(a) lo noto en partes } \\
\text { específicas de mi cuerpo. }\end{array}$ & 0.46 & 0.60
\end{tabular}

\section{Not-Distracting}

$5 \quad$ Noto la tensión física o el malestar solamente $\quad 0.53 \quad 0.66$ cuando se vuelve muy severo.

$6 \quad$ No me doy cuenta de las sensaciones de malestar. $\quad 0.43 \quad 0.39$

$7 \quad$ Cuando siento dolor o malestar intento ignorarlo y $\quad 0.43 \quad 0.51$ continuar con lo que estaba haciendo.

\section{Not-Worrying}

$9 \quad$ Si siento algún malestar me empieza a preocupar $\quad 0.23 \quad 0.45$ que algo no ande bien.

10 Puedo sentir alguna sensación física desagradable $\quad 0.48 \quad 0.60$ sin preocuparme por ella.

\section{Attention Regulation}

11 Puedo prestar atención a mi respiración sin ser

$0.69 \quad 0.71$

distraído(a) por lo que pasa a mi alrededor.

12 Puedo tener conciencia de mis sensaciones 0.690 .81 corporales internas aun cuando hay muchas cosas sucediendo a mi alrededor.

13 Cuando estoy conversando con alguien puedo prestarle atención a mi postura.

14 Puedo volver a concentrarme en mi cuerpo si estoy distraído(a)

15 Puedo re-dirigir mi atención desde mis pensamientos a mis sensaciones corporales.

16 Puedo prestar atención a todo mi cuerpo incluso cuando una parte de mi siente dolor o malestar.

17 Soy capaz de concentrarme conscientemente en mi cuerpo de manera global.

$0.79 \quad 0.86$

$0.66 \quad 0.65$

\begin{tabular}{llcl} 
Emotional Awareness & FL & C \\
\hline $18 \quad \begin{array}{l}\text { Noto cómo mi cuerpo cambia cuando estoy } \\
\text { enojado(a). }\end{array}$ & 0.58 & 0.75 \\
$19 \quad \begin{array}{l}\text { Cuando algo anda mal en mi vida puedo sentirlo } \\
\text { en mi cuerpo. }\end{array}$ & 0.51 & 0.71 \\
20 & $\begin{array}{l}\text { Noto que mi cuerpo se siente diferente después } \\
\text { de una experiencia apacible. }\end{array}$ & 0.75 & 0.76 \\
$\quad \begin{array}{l}\text { Noto que puedo respirar libre y fácilmente } \\
\text { cuando me siento cómodo(a). }\end{array}$ & 0.78 & 0.73 \\
$\quad \begin{array}{l}\text { Noto cómo mi cuerpo cambia cuando me siento } \\
\text { contento(a)/feliz. }\end{array}$ & 0.82 & 0.89
\end{tabular}

\section{Self-Regulation}

23 Cuando me siento sobrepasado(a) puedo $0.62 \quad 0.78$ encontrar un lugar tranquilo dentro de mi.

24 Cuando dirijo la atención hacia mi cuerpo siento $\quad 0.80 \quad 0.86$ calma.

25 Puedo utilizar mi respiración para reducir la $\quad 0.81 \quad 0.99$ tensión.

26 Cuando estoy atrapado(a) en mis pensamientos $0.85 \quad 0.85$ puedo calmar mi mente concentrándome en mi cuerpo/respiración.

\section{Body Listening}

$\begin{array}{llll}27 & \text { Estoy a la escucha de la información que envía } & 0.77 & 0.95 \\ & \text { mi cuerpo sobre mi estado emocional. } & & \\ 28 & \begin{array}{l}\text { Cuando estoy alterado(a), me tomo el tiempo } \\ \text { para explorar cómo se siente mi cuerpo. }\end{array} & 0.79 & 0.83 \\ 29 & \text { Escucho a mi cuerpo para saber qué hacer. } & 0.70 & 0.73\end{array}$

\section{Trusting}

30 En mi cuerpo, estoy en casa.

$0.80 \quad 0.90$

31 Siento que mi cuerpo es un lugar seguro.

$0.97 \quad 0.95$

32 Confío en mis sensaciones corporales.

$0.68 \quad 0.78$

Method for factor extraction: ML, Maximum Likelihood; Method the rotation: Normalized Promax. FL, Factor loading; C, Communality.

items varied from.43 to.97, which were considered satisfactory. The goodness of fit statistics of the model were $\chi^{2}{ }_{(223)}=327.337$ $(p<0.001)$, a CFI $=0.96$, a GFI $=0.99$, a TLI $=0.93$ and $\mathrm{a}$ RMSEA $=0.046$.
The observed $\chi^{2}$ value leads us to reject the hypothesis of an exact fit of the model. Considering that this statistic has the tendency to reject models when working with samples moderate to large in size (West et al., 2012), and the satisfactory values for the 
other indices, the results indicate a good fit for the eight factors model.

The reliability of the total scale based on the 30 items is 0.90 (Cronbach's alpha based on standardized elements $=0.91$, with reliability coefficients that vary between 0.40 and 0.86 ).

The subscale-subscale correlations analysis indicates higher associations between Self Regulation and Body Listening ( $r=0.681, p<0.01)$ and between Attention Regulation and Body Listening $(r=0.654, p<0.01)$. The Not-Distracting subscale correlates poorly with Trusting $(r=0.189, p<0.01)$ and demonstrates an inverse correlation with Not-Worrying $(r=-0.133$, $p<0.05)$. Not-Worrying does not show significant correlations with the other subscales. The item-scale correlations belonging to the subscales Not-Worrying and Not-Distracting have scores between -0.078 and 0.107 . This indicates that these items do not differentiate people with high and low scores on the total scale. Correlations and reliability values for each subscale are presented in Table 4.

The second step of the analysis consisted in using the validation sample to perform CFA of the eight factors model. Through the CFA four models were built. Model 1 had eight correlated factors with factors loadings in the range of 0.35 and 0.96 . Not all factors were significant. Model 2 included the covariance between the errors of the items $1-2,1-3,12-15,13-14,18-19$, and 25-26. Item 6 was removed due to its low factorial load. This model yielded factor loadings between 0.40 and 0.97 , all statistically significant $(p<0.001)$. This model had better indicators of goodness of fit than model 1. Model 3 preserved the covariance that had been incorporated in model 2 but eliminated the covariance between the factors Not-Worrying and Trusting; Not-Worrying and Attention Regulation; and Not-Worrying and Emotional Awareness. The indicators of goodness of fit did not significantly improve in this model. Finally, Model 4 removed the Not-Distracting factor: after removal of the covariance between this factor and other factors of the scale, the items of Not-Distracting resulted insignificant. The indicators of goodness of fit did not improve in this model. Goodness of fit statistics of the four models are presented in Table 5.

The various models achieved through CFA present goodness of fit statistics similar to those of the original scale (Mehling et al., 2012). Model 2 presents significant factor loadings for the eight factors and the best goodness of fit statistics, therefore it was accepted as the model that best fits the data (see Figure 1).

\section{DISCUSSION}

The aim of this study was to translate and adapt the MAIA into the Sapanish language, and to assess its psychometric properties in a Spanish speaking population. The Spanish tool was tested in a sample of 470 participants aged between 18 and 70 years, from the provinces of Valparaíso and Concepción, Chile. The adaptation was developed using a forward-backward translation, preserving the extension, format and the dimensional structure of the original scale. The cognitive interviews indicate comprehensiveness in most items. We identified difficulties in comprehension for items $5,6,7$, and 15 . Item 5 was reworded in order to avoid negation. Item 7 was reworded in order to better match the original meaning.

Table 4 | Pearson product-moment correlations among the eight MAIA scales and Cronbach's alpha.

\begin{tabular}{|c|c|c|c|c|c|c|c|c|}
\hline & 1 & 2 & 3 & 4 & 5 & 6 & 7 & 8 \\
\hline 1. Noticing & 0.637 & & & & & & & \\
\hline 3. Not-Worrying & -0.010 & $-0.133^{*}$ & 0.402 & & & & & \\
\hline 4. Attention Regulation & $0.474^{* *}$ & 0.090 & 0.018 & 0.861 & & & & \\
\hline 7. Body Listening & $0.399 * *$ & 0.113 & -0.031 & $0.654^{* *}$ & $0.437 * *$ & $0.681 * *$ & 0.832 & \\
\hline 8. Trusting & $0.294 * *$ & $0.189 * *$ & -0.021 & $0.519 * *$ & $0.330 * *$ & $0.577 * *$ & $0.547 * *$ & 0.855 \\
\hline
\end{tabular}

Cronbach's alpha on the diagonal.

${ }^{*} p<0.05,{ }^{* *} p<0.01$ (bilateral).

Table 5 | Confirmatory factor analyses model fit indices.

\begin{tabular}{|c|c|c|c|c|c|c|c|}
\hline & S-B $\chi^{2}$ & $d f$ & $p$ & CFI & TLI & RMSEA (IC 90\%) & SRMR \\
\hline Model 1 & 754.545 & 377 & 0.0001 & 0.894 & 0.878 & $0.063(0.057-0.070)$ & 0.060 \\
\hline Model 2 & 659.778 & 371 & 0.0001 & 0.919 & 0.905 & $0.056(0.049-0.063)$ & 0.059 \\
\hline Model 3 & 658.721 & 375 & 0.0001 & 0.908 & 0.905 & $0.056(0.054-0.065)$ & 0.059 \\
\hline Model 4 & 744.200 & 347 & 0.0001 & 0.919 & 0.908 & $0.060(0.053-0.068)$ & 0.072 \\
\hline
\end{tabular}

This fit-index was estimated with AMOS-18. 




FIGURE 1 | Structural model of adaptation to Spanish of multidimensional assessment of interoceptive awareness (MAIA). Path diagram model 2 , standardized estimates.

The EFA favored a model with a factorial structure of eight dimensions with low factorial loading for items 8 and 9. Items 4 and 8 were removed because they did not contribute to the factors that they theoretically belong to. A new rotated factorial matrix was established for the 30-item scale. This matrix showed a factorial structure of eight dimensions, similar to the original instrument, but with minor loading for item 9. We observed higher factorial loadings for item 9 as the sample size increased, we therefore decided to keep this item to preserve the dimension Not-Worrying.
The low contribution of item 4 (Noto cambios en mi respiración tales como cuando se hace más lenta o más rápida, [I notice changes in my breathing. such as whether it slows down or speeds up.]) to the subscale Noticing might be due to the order of this item following three items that refer explicitly to the experience of noticing a particular sensation in the body. The content of item 4 could be interpreted as relating to a "function" of the body rather than to the body itself.

The low contribution of item 8 (Cuando siento dolor físico me enojo, [When I feel physical pain. I become upset]) to the subscale 
Not-Worrying might be due to a translation issue. The word "upset" was translated as "enojo": this word refers to the emotion anger and not to worry, which is what the subscale assesses. It is challenging to convey the meaning of 'upset' as used in English in the Spanish language.

Five of the eight scales showed alphas above 0.8 , which indicate a good internal consistency. The reliability of the subscales Noticing (0.637), Not-Distracting (0.487) and Not-Worrying (0.402) is questionable. The reliability of the subscale Noticing was lower than found by Mehling et al., 2012 (0.69), Mehling et al., 2013 (0.74) and Bornemann et al., 2014 (0.76). Removing item 4 and reducing the subscale Noticing to three items might have weakened its reliability. Reliability usually increases when the number of items in the scale is increased (Cohen and Swerdlik, 2006). Low reliability of the subscale Not-Distracting might be due to: (a) the formulation using negation of item 6; (b) the small number of items in this subscale; and (c) the underlying construct. According to Mehling et al. (2012), the Not-Distracting subscale assesses the tendency not to use distraction to cope with discomfort, or not to ignore nor power through unpleasant sensations: these, in theory, are related to higher body awareness. In other words, this subscale assesses the ability to acknowledge, observe and attend unpleasant sensations. However, formulating this construct in its reverse form might lead to confusion; under certain circumstances I prefer to ignore a given sensation does not necessarily mean $I$ am unable to acknowledge it and to be aware of it. It is unclear if "Cuando siento dolor o malestar intento ignorarlo y continuar con lo que estaba haciendo" [When I feel pain or discomfort, I try to ignore it and to carry on with what I was doing] means I do not acknowledge the sensation. It might simply mean that even if I acknowledge it, it doesn't paralyze me and I can carry on with what I was doing. This subscale also presented low consistency in the English $(0.66$ in Mehling et al., 2012; 0.48 in Mehling et al., 2013) and German versions (0.56 in Bornemann et al., 2014), which might indicate that the underlying construct needs revision. The other possibility is that this subscale appears clearer to a particular sub-group, such as experts of body-mind practices. The results of the studies mentioned prior also support this possibility.

The low number of items (two), one with very low loading, likely explains the low consistency observed in the Not-Worrying subscale. Others have also observed low consistency here $(0.67$ in Mehling et al., 2012; 0.58 in Mehling et al., 2013; and 0.65 in Bornemann et al., 2014).

Subscale-subscale correlations analysis showed moderately high correlations between Body Listening and all the other subscales except Not-Worrying and Not-Distracting. These two subscales showed no correlation or low correlation with all other subscales. Mehling et al. (2013) report similar findings, indicating high association between Body Listening and Self-Regulation, and Body Listening and Emotional Awareness, as well as a lack of correlation of Not-Distracting and Not-Worrying with the other subscales.

The CFA supported a factorial structure of eight dimensions with goodness of fit statistics similar to the original scale.

One limitation of the present study is the small sample size and the relative lack of its representativeness biased by sex and educational level. The small sample size affects the conformation of the factorial structure and hinders the goodness of fit of the model, which has factorial loadings close to 0.40 , at the limit for samples of around 200 participants (Hair et al., 2010; Lloret-Segura et al., 2014). This effect is particularly noticeable in item 9, where the load factor improved when larger samples sizes were modeled in the EFA.

While the translation and adaptation of the instrument was conducted considering various international guidelines, such as those outlined by Muñiz etal. (2013), it is suggested to continue the linguistic adjustment, particularly for items 6 and 8 , which mainly affect the Not-Distracting and the Not-Worrying subscales: the reverse structure of these might pose added difficulty for respondents (Hartley, 2013). These factors have less than the minimum three items and thus threaten the dimension assessment (Long, 1983; Bollen, 1989; Abad et al., 2011), affecting the reliability of the subscales. In several solutions, these items did not reach sufficient statistical significance to load for a factor. This resulted in overlapping of the dimensions in some solutions, while grouping others into a single factor, hence, not discriminating satisfactorily.

We recommend reconsidering the order of the items in the scale. In the MAIA items are grouped by subscales and not randomly distributed as in Likert scales. Ordering items randomly prevents the establishment of a pattern of automatic responses. This also applies for reverse items, which were grouped within two subscales (Not-Distracting and Not-worrying), rather than being randomly distributed.

Regarding the questionable behavior of the Not-Distracting and Not-Worrying subscales, and that difficulties in these scales have been reported in other studies, we suggest revising these items. One solution could be to include items that better assess the construct measured by these factors, for example reverse items in their affirmative forms. Further, adding items in these subscales to include a minimum of four per factor might aid to promote the internal consistency of the scale, and its reliability.

Future development of the MAIA in the Chilean population should explore and provide evidence for convergent and divergent validity. Further studies with clinical and non-clinical populations, or samples with specific characteristics, are required to explore the differential performance of the items. Finally, applying item response theory (IRT) to model individual subject responses for a given ability may further enhance research efforts in this population. These developments would facilitate the future use of the scale in a professional context, beyond the research setting.

\section{CONCLUSION}

The Spanish version of the MAIA showed satisfactory psychometric properties. An eight-factor model was built from the EFA, similar to the original scale. CFA confirmed the eight correlated factors model (Model 2). This model shows satisfactory goodness of fit statistics: $\chi^{2}{ }_{(371)}=659.78, p=0.0001$; CFI $=0.92$, $\mathrm{TLI}=0.91$ and RMSEA $=0.056$ (IC 90\%: 0.049-0.063). Altogether, these indices support the adequacy of the eight-factor model, with a goodness of fit similar to the original scale.

Regarding the subscales Not-Worrying and Not-Distracting, the low value of their reliability coefficients, the covariance 
between the errors for some items and the low factor loadings suggest a revision of these is warranted.

To conclude, the present study shows that the Spanish adaptation of MAIA is an appropriate tool to assess interoceptive awareness in the Chilean population. This favors the use of this tool for research purposes, and provides the possibility to study variables associated with psychological well-being, physical well-being and other interventions in the field of human health.

\section{ACKNOWLEDGMENTS}

This work was supported by CONICYT (Comisión Nacional de Investigación Científica y Tecnológica) - PAI (concurso nacional de apoyo al retorno de investigadores desde el extranjero)- FOLIO 82130040 .

\section{REFERENCES}

Abad, F. J., Olea, J., Ponsoda, V., and García, C. (2011). Medición en Ciencias Sociales $y$ de la Salud. Madrid: Editorial Síntesis.

Bollen, K. A. (1989). Structural Equations with Latent Varibles. New York, NY: Wiley. doi: 10.1002/9781118619179

Bornemann, B., Herbert, B. M., Mehling, W. E., and Singer, T. (2014). Differential changes in self-reported aspects of interoceptive awareness through three months of contemplative training. Front. Psychol. 5:1504. doi: 10.3389/fpsyg.2014. 01504

Chow, Y. W. Y., and Tsang, H. W. H. (2007). Biopsychosocial effects of qigong as a mindful exercise for people with anxiety disorders: a speculative review. J. Altern. Complement. Med. 13, 831-839. doi: 10.1089/acm.2007.7166

Cohen, R. J., and Swerdlik, M. E. (2006). Pruebas y Evaluación Psicológicas. Introducción a las Pruebas y a la Medición, 6th Edn. México: McGraw Hill.

Craig, A. D. (2002). How do you feel? Interoception: the sense of the physiological condition of the body. Nat. Rev. Neurosci. 3, 655-666. doi: 10.1038/nrn894

Davis, L. W., Strasburger, A. M., and Brown, L. F. (2007). Mindfulness: an intervention for anxiety in schizophrenia. J. Psychosoc. Nurs. Ment. Health Serv. 45, 23-29.

Ditto, B., Eclache, M., and Goldman, N. (2006). Short-term autonomic and cardiovascular effects of mindfulness body scan meditation. Ann. Behav. Med. 32, 227-234. doi: 10.1207/s15324796abm3203-9

Ehlers, A., and Breuer, P. (1992). Increased cardiac awareness in panic disorder. J. Abnorm. Psychol. 101, 371-382. doi: 10.1037/0021-843X.101.3.371

Forero, C. G., Maydeu-Olivares, A., and Gallardo-Pujol, D. (2009). Factor analysis with ordinal indicators: a monte carlo study comparing DWLS and ULS estimation. Struct. Equ. Modeling 16, 625-641. doi: 10.1080/10705510903203573

Hair, J. F., Black, W. C., Babin, B. J., and Anderson, R. E. (2010). Multivariate Data Analysis, 7th Edn. Wilmington, DE: Pearson Prentice Hall.

Hartley, J. (2013). Some thoughts on Likert-type scales. Int. J. Clin. Health Psychol. $13,83-86$.

Hu, L., and Bentler, P. M. (1999). Cutoff criteria for fit indexes in covariance structure analysis: conventional criteria versus new alternatives. Struct. Equ. Modeling 6, 1-55. doi: 10.1080/10705519909540118
Kabat-Zinn, J. (2008). Full Catastrophe Living: Using the Wisdom of Your Body and Mind to Face Stress, Pain, and Illness. 15th Edn. New York, NY: Random House.

Kline, R. B. (2011). Principles and Practice of Structural Equation Modeling, 3rd Edn. New York, NY: Guilford Press.

Lloret-Segura, S., Ferreres-Traver, A., Hernández-Baeza, A., and Tomás-Marco, I. (2014). El análisis factorial exploratorio de los ítems: una guía práctica, revisada y actualizada. Anal. Psicol. 30, 1151-1169. doi: 10.6018/analesps.30.3.199361

Long, J. S. (1983). Confirmatory Factor Analysis. Newbury Park, CA: Sage.

Lorenzo-Seva, U., and Ferrando, P. J. (2006). FACTOR: a computer program to fit the exploratory factor analysis model. Behav. Res. Methods Instrum. Comput. 38, 88-91. doi: 10.3758/BF03192753

Mehling, W. E., Daubenmier, J., Price, C. J., Acree, M., Bartmess, E., and Stewart, A. L. (2013). Self-reported interoceptive awareness in primary care patients with past or current low back pain. J. Pain Res. 6, 403-418. doi: 10.2147/JPR.S42418

Mehling, W. E., Price, C., Daubenmier, J. J., Acree, M., Bartmess, E., and Stewart, A. (2012). The multidimensional assessment of interoceptive awareness (MAIA). PLoS ONE 7:e48230. doi: 10.1371/journal.pone.0048230

Morone, N. E., Greco, C. M., and Weiner, D. K. (2008). Mindfulness meditation for the treatment of chronic low back pain in older adults: a randomized controlled pilot study. Pain 134, 310-319. doi: 10.1016/j.pain.2007.04.038

Muñiz, J., Elosua, P., and Hambleton, R. (2013). Directrices para la traducción y adaptación de los test: segunda edición. Psicothema 25, 151-157. doi: 10.7334/psicothema2013.24

Rosenzweig, S., Reibel, D. K., Greeson, J. M., Edman, J. S., Jasser, S. A., McMearty, K. D., etal. (2007). Mindfulness-based stress reduction is associated with improved glycemic control in type 2 diabetes mellitus: a pilot study. Altern. Ther. Health Med. 13, 36-38.

Schandry, R. (1981). Heart beat perception and emotional experience. Psychophysiology 18, 483-488. doi: 10.1111/j.1469-8986.1981.tb02486.x

Sherrington, C. S. (1906). The Integrative Action of the Nervous System. New York: C Scribner's sons.

West, S. G., Taylor, A. B., and Wu, W. (2012). "Model fit and model selection in structural equation modeling," in Handbook of Structural Equation Modeling, ed. R.H. Hoyle (New York, NY: Guilford Press), 209-231.

Conflict of Interest Statement: The authors declare that the research was conducted in the absence of any commercial or financial relationships that could be construed as a potential conflict of interest.

Received: 31 December 2014; accepted: 22 January 2015; published online: 11 February 2015.

Citation: Valenzuela-Moguillansky C and Reyes-Reyes A (2015) Psychometric properties of the multidimensional assessment of interoceptive awareness (MAIA) in a Chilean population. Front. Psychol. 6:120. doi: 10.3389/fpsyg.2015.00120

This article was submitted to Consciousness Research, a section of the journal Frontiers in Psychology.

Copyright () 2015 Valenzuela-Moguillansky and Reyes-Reyes. This is an open-access article distributed under the terms of the Creative Commons Attribution License (CC BY). The use, distribution or reproduction in other forums is permitted, provided the original author(s) or licensor are credited and that the original publication in this journal is cited, in accordance with accepted academic practice. No use, distribution or reproduction is permitted which does not comply with these terms. 